\title{
CARACTERIZAÇÃO DE BOLO E BISCOITO ADICIONADO DE FARINHA DE BANANA VERDE DE DIFERENTES VARIEDADES
}

\author{
Rita de Cássia Sampaio Santana ${ }^{1}$; Renato Souza $\mathrm{Cruz}^{2}$ \\ 1. Bolsista PIBIC/CNPq, Graduando em Engenharia de Alimentos, Universidade Estadual de Feira de Santana, \\ e-mail: rcassia.santana@outlook.com \\ 2. Orientador, Departamento de tecnologia, Universidade Estadual de Feira de Santana, e-mail: cruz.rs@gmail.com
}

PALAVRAS-CHAVE: banana verde, amido resistente, alimento funcional.

\section{INTRODUÇÃO}

A resolução $\mathrm{n}^{\circ}$ 12/1978 define o biscoito ou bolacha como sendo o produto obtido pelo amassamento e cozimento conveniente de massa preparada com farinhas, amidos, féculas fermentadas, ou não, e outras substâncias alimentícias.

Alimento funcional é o alimento ou ingrediente que não apresenta apenas funções nutritivas básicas, sendo também capaz de produzir efeitos metabólicos e/ou fisiológicos benéfico à saúde (BRASIL, 1999). Dentre os alimentos funcionais podem-se citar as fibras alimentares, sendo esta qualquer material comestível que não seja hidrolisado pelas enzimas endógenas do trato digestivo humano (BRASIL, 2003).

O amido resistente possui comportamento semelhante ao da fibra alimentar, tendo relação com os efeitos benéficos locais, prioritariamente no intestino grosso, e sistêmico, por intermédio de uma série de mecanismos (LOBO e LEMOS SILVA, 2003). Segundo estudos de Kayisu e Hood (1981), a banana verde apresenta amido resistente demonstrando comportamento similar ao da fibra alimentar.

Este trabalho teve como objetivo a elaboração de biscoitos com incorporação da farinha de banana verde a farinha de trigo, com intuito de associar valor nutricional a estes produtos, desenvolvendo assim produtos alimentícios com elevado teor de amido resistente, realizando a mínima interferência na sua qualidade tecnológica. Possibilitando a caracterização da farinha e do produto final.

\section{MATERIAL E MÉTODOS OU METODOLOGIA (ou equivalente)}

A farinha de trigo, ovos, açúcar, sal, margarina e o leite foram obtidos no mercado local e a farinha de banana verde foi fornecida pela EMBRAPA Mandioca e Fruticultura.

Foi determinada a umidade da farinha em balança de infravermelho de acordo com Instituto Adolfo Lutz (2004). Para a determinação do tamanho das partículas seguiu a metodologia segundo por Germani, Benassi e Carvalho (1997). A capacidade de absorção de água (CAA) foi determinada segundo método descrito por Sosulski (1962) citado por Wang (2006), sendo utilizadas as proporções de 5\%,10\%, 15\%, $20 \%$ e $25 \%$ de farinha de banana.

O preparo dos biscoitos consistiu em misturar inicialmente $75 \mathrm{~g}$ de açúcar e $60 \mathrm{~g}$ de gordura por quatro minutos em velocidade media, em batedeira planetária (Arno), adicionando em seguida dois ovos e homogeneizando a massa por mais um minuto em velocidade media. Por fim, adicionou toda a farinha, sendo $300 \mathrm{~g}$ de farinha de trigo e variando os níveis de farinha de banana verde nas proporções de $0 \%$ (F0), 7,5\% (F1) e 15\% (F2) com relação à proporção de $100 \%$ de farinha de trigo que foi mantida constante, seguida de $1,5 \mathrm{~g}$ de sal, misturando por mais quatro minutos em velocidade baixa. A massa foi moldada em formato retangular, de aproximadamente $2 \mathrm{~cm}$ de largura. As massas foram levadas para assamento a $180^{\circ} \mathrm{C}$ por 40 minutos em forno elétrico (Metalnox) preaquecido. 
Gerou-se 12 amostras para cada repetição realizada para cada formulação, destas, 6 foram utilizadas para a análise do perfil de textura dos biscoitos e as outras 6 para a determinação dos parâmetros de peso e volume.

Determinou-se a perda de peso e volume especifico dos biscoitos de acordo com o Método 10-50 D (AACC, 2000). A textura dos biscoitos foi determinada 24 horas após a cocção, sendo analisada em texturômetro TA.XT.plus, utilizando o software Exponent Stable. Analisando os parâmetros de Dureza e fraturabilidade. As condições do teste foram: velocidade do pré-teste $=2,5 \mathrm{~mm} \cdot \mathrm{s}-1$, velocidade do teste $=2,0 \mathrm{~mm} \cdot \mathrm{s}-1$, do pós-teste $=10,0 \mathrm{~mm} \cdot \mathrm{s}-1$, força de contato $=50 \mathrm{~g}$. O experimento foi conduzido em delineamento inteiramente casualizado com três repetições, sendo os dados analisados por teste de média, Tukey a $5 \%$ de probabilidade.

\section{RESULTADOS E/OU DISCUSSÃO (ou Análise e discussão dos resultados)}

A farinha de banana verde apresentou teor de umidade de $12,02 \%$, estando dentro do limite aceitável pela ANVISA que é de $15 \%$ (BRASIL, 2005). Observou-se que 59,86\% da farinha de banana verde apresentou granulometria inferior a $0,090 \mathrm{~mm}$, apresentando granulometria menor que a da farinha de trigo, visto que segundo a portaria $\mathrm{n}^{\circ} 354$, de 18 de julho de 1996, 98\% da farinha de trigo comum deve passar através de uma peneira com abertura de malha de $250 \mu \mathrm{m}(0,250 \mathrm{~mm})$. A distribuição granulométrica encontrada para a farinha de banana não foi homogênea, no entanto a uniformidade na granulométrica é um fator de maior importância que o próprio tamanho das partículas, pois favorece uma melhor distribuição da água pela massa (HOSENEY e ROGERS, 1990)

. Nota-se que a formulação contendo maior teor de farinha de banana verde (F5) foi a que apresentou maior capacidade de absorção de água, o que pode ser justificado pela presença de fibras. Acredita-se que este aumento na absorção de água ocorra por conta da maior disponibilidade de grupos hidrofílicos que se ligam às moléculas de água (Wang et al., 2009). Sendo este aumento benéfico para formulações de produtos de panificação, pois permite maior incorporação de água à massa e aumenta o rendimento dos produtos finais (PEREZ e GERMANI, 2004).

Para as análises de perda de perda e volume especifico dos biscoitos obteve-se média de $20,12 \% \pm 0,51$ e 2,45 $\pm 0,10$, respectivamente. Sendo que em ambas não se observou diferença estatística entre os tratamentos $(\mathrm{p}<0,05)$. A variação de peso antes e após a cocção dos biscoitos fornece a perda de umidade no assamento (Pissato, 2010). Fasolin et al. (2007) ao incorporar FBV em biscoitos cookies, observou uma maior variação nas formulações contendo maior incorporação (20 e 30\%), o que pode indicar uma menor capacidade de retenção de água pelos componentes da massa do biscoito após a adição de maiores quantidades de FBV. O volume específico dos biscoitos é afetado por vários fatores como a qualidade dos ingredientes utilizados na formulação da massa, especialmente a farinha e as condições de tratamento usado durante o processamento (MOURA et al., 2010).

A dureza é a força necessária para produzir certa deformação, podendo ser relacionada à mastigação humana como sendo a força para comprimir uma amostra entre os dentes molares ou entre a língua e o palato. Enquanto o parâmetro fraturabilidade é a força pela qual o material fratura ou uma amostra esmigalha, racha ou se quebra em pedaços, um produto com alto grau de dureza e baixo grau de coesividade (CIVILLE e SZCZESNIAK, 1973). Os resultados dos parâmetros de textura dos biscoitos: dureza e fraturabilidade demonstraram que não houve diferença significativa entre os tratamentos com média para dureza = $7947,49 \pm 529,45$ e fraturabilidade $=0,64 \pm 0,085$. A dureza é um dos fatores que determina a aceitabilidade do alimento pelo consumidor e, assim como a fraturabilidade, é desejável que seus valores sejam baixos (Assis et al., 2009). 


\section{CONSIDERAÇÕES FINAIS (ou Conclusão)}

A incorporação das proporções de $7,5 \%$ e $15 \%$ de farinha de banana verde para elaboração dos biscoitos permitiu a sua formulação com características similares a formulação controle com $0 \%$ de incorporação, não apresentando diferença significativa dos parâmetros analisados no presente trabalho. Sendo assim, mostrou-se possível a sua utilização para formulação de produto panificável possibilitando uma melhoria na qualidade nutricional realizando a mínima interferência na qualidade tecnológica do produto final. Visto que, a literatura indica um elevado teor de amido resistente presente, tendo ainda como benefício que esta não possui sabor característico, portanto, não alterando suas características sensoriais.

\section{REFERÊNCIAS}

AMERICAN ASSOCIATION OF CEREAL CHEMISTS - AACC. Approved Methods of the American Association of Cereal Chemists. 10. ed. Saint Paul: AACC, 2000. CD-ROM. ASSIS, L. M. et al. Propriedades nutricionais, tecnológicas e sensoriais de biscoitos com substituição de farinha de trigo por farinha de aveia ou farinha de arroz parabolizado.

Alimentos e Nutrição, Araraquara, v. 20, n. 1, p. 15-24, 2009.

BRASIL. Resolução n.12- CNNPA, de 24 de julho de 1978. A Comissão Nacional de Normas e Padrões para Alimentos do Ministério da Saúde aprova 47 padrões de identidade e qualidade relativos a alimentos e bebidas para serem seguidos em todo território brasileiro. Diario Oficial da União, Brasilia, 24 Jul.,1978. Seção1. BRASIL. ANVISA. Agencia Nacional de Vigilância Sanitária. Resolução RDC n 18, de 30 de abril de 1999. Diretrizes básicas para análise e comprovação de propriedades funcionais e ou de saúde alegadas em rotulagem de alimentos.

BRASIL. ANVISA. Agencia Nacional de Vigilância Sanitária. Resolução RDC ANVISA no 360 de 23 de novembro de 2003. Aprova o "Regulamento Técnico sobre Rotulagem Nutricional de Alimentos Embalados", tornando Obrigatório a rotulagem Nacional. BRASIL. Resolução n²63, de 22 de setembro de 2005. Aprova regulamento técnico para produtos de cereais, amidos, farinhas e farelos. Diário Oficial da Republica Federativa do Brasil, Brasília, DF, 22 set. 2005. Disponível em: http://www.anvisa.gov.br. Acesso em 12 abr. 2017.

CIVILLE, C. V.; SZCZESNIAK, A. S. Guidelines to training a texture profile panel. Journal of Texture Studies, Westport, v. 4, n. 2, p. 204-223, 1973.

HOSENEY, R. C.; ROGERS, D. E. The formation and properties of wheat flour doughs. Food Science and Nutrition, Saint Paul, v. 26, n. 2, p. 73-93, 1990.

Lobo,A.R.; LEMOS SILVA ,G.M. Amido resistente e suas propriedades físico químicas. Rev.Nutr., Campinas, v. 16, n.2 , abr./jun. 2003.

KAYISU, K.; HOOD, L. F. Molecular structure of banana starch. Journal of Food Science, v.46, p.1894 - 1897, 1981.

FASOLIN, L. H. et al. Biscoitos produzidos com farinha: avaliações química, física e sensorial. Ciência e Tecnologia de Alimentos, v. 27, n. 3, p. 524-529, 2007. GERMANI, R.; BENASSI, V. T.; CARVALHO, J. L. V. Métodos de avaliação de grão e farinha de trigo. Rio de Janeiro: Embrapa, 1997. 84 p. Documentos, n. 28, BRASIL.

INSTITUTO ADOLFO LUTZ. Métodos químicos e físicos para análise de alimento. 4.ed. São Paulo: Normas analíticas do Instituto Adolfo Lutz,2004.v.1,989p.

MOURA, F.A. et al. Biscoitos tipo "cookie" elaborados com diferentes frações de semente de abóbora (Curcubita maxima). Alimentos e Nutrição, Araraquara, v. 21, n. 4, p. 579-585. 2010.

PEREZ, P. M. P.; GERMANI, R. Farinha mista de trigo e berinjela: características físicas e químicas. Bol. CEPPA, Curitiba, v. 22, n. 1, p.24, 2004. 
PISSATO, A. Desenvolvimento de um biscoito tipo cookie enriquecido com cálcio e

vitamina D. Dissertação de Mestrado, Setor de Tecnologia, UFPR, Curitiba, 93 p., ago, 2010. SOSULSKI, F.W. The centrifuge method for determining flour absorption in hard red spring wheats. Cereal Chemistry, St. Paul, v.39, n. 4, p. 344-350, 1962.

WANG, S. H.; BATISTA, G. S.; NASCIMENTO, T. P.; NASCIMENTO, K. O.;

NASCIMENTO, M. R. F. Efeitos dos parâmetros de extrusão na absorção de água e absorção de gordura de farinhas extrusadas de trigo e soja. Alimentos e Nutrição, v.20, n.4, p. 641647, 2009. 